\title{
Association of Serum Zinc level with Pre Eclampsia
}

\author{
Ali Raza Memon, Fareen Waryal Memon, Muhammad Akram, \\ Paras Javed Memon, Irtiza Rahman
}

\begin{abstract}
BACKGROUND: Pre eclampsia is the commonest obstetrical complication in pregnant women. The etiology of pre eclampsia has yet not been clearly understood. It has a worldwide prevalence of 2-10\% of pregnancies and one of the major causes of increase in maternal and perinatal morbidity and mortality. Zinc plays an important role in the course and eventual outcome of human pregnancy and is essential for normal embryogenesis and fetal growth. Zinc deficiency in pregnancy is thought to be associated with pre-eclampsia.
\end{abstract}

OBJECTIVE: The aim of this study was to investigate the serum zinc level in pre-eclampsia.

PATIENTS AND METHODS: This Hospital based study conducted at Gynecology Department of Indus Medical Collage, Tando Muhammad Khan, Sindh from October 2015 to March 2016 with the Permission of Head of the Department and Principal of Institute. The study groups consist of 40 consecutive diagnosed cases of pre eclampsia and $\mathbf{4 0}$ women with normal pregnancies. The serum zinc level of the subjects under this study was determined using Atomic Absorption Spectrophotometer.

RESULTS: The results of our study showed that serum Zinc level among the pre-eclamptic and was statistically significantly low as compared to normotensive pregnant women.

CONCLUSION: The findings of current work are statistically significant to establish that concentration of serum zinc among preeclamptic subjects is lower than in the normotensive women during pregnancy.

KEYWORDS: Serum zinc, Pre eclampsia, Pregnancy.

This article may be cited as: Memon AR, Memon FW, Akram M, Memon PJ, Rahman I. Association of Serum Zinc level with Pre Eclampsia. J Liaquat Uni Med Health Sci. 2017;16(01):58-61. doi: 10.22442/jlumhs. 171610507

\section{INTRODUCTION}

Pre eclampsia is defined as "increased blood pressure along with protein appearance in urine with or without pedal edema in the $3^{\text {rd }}$ trimester of pregnancy". ${ }^{1}$ Increase blood pressure is defined as systolic B.P more than $140 \mathrm{mmHg}$ and diastolic more than 90 $\mathrm{mmHg}$ at least on two different readings within 6 hours $^{2,3}$. All over the world, pre eclampsia is the $3^{\text {rd }}$ leading cause of mother's mortality ${ }^{4}$. At least 6 million mothers died per year due to different complications of gravida period, and preeclampsia is the leading cause of maternal death in all over the world ${ }^{4}$.The prevalence of pre eclampsia has been reported to be $15 \%$ in one study from pakistan ${ }^{5}$.

In developing countries there is deficiency of nutrients especially minerals during pregnancies and these deficiencies may contribute in the development of many complications like pre eclampsia". "Zinc is one of the important micro mineral which plays many important physiological functions during pregnancy like development of embryo, growth of fetus, antiseptic action in the amniotic fluid, contraction of uterus and initiation of labour $\mathrm{etc}^{7}$. Many important cellular functions and reproductive health is also influenced by zinc deficiency because it takes part as co-enzyme in more than 300 biochemical reactions".

Many researches suggested that low serum zinc level can cause fetal malformations, growth restriction of fetus, preterm birth of child, pre eclampsia etc. ., $10^{2}$ Studies conducted in preeclampsia with respect to serum Zinc reported contrasting results, it is reported as decreased ${ }^{11}$, increased ${ }^{12}$ and normal ${ }^{13}$.

In this study we measure and compared serum zinc in pre eclampsia with pregnant mothers without preeclampsia.

\section{MATERIALS \& METHODS}

This comparative study was carried out at Gynecology department of Indus Medical collage and Hospital, Tando Muhammad Khan, Sindh from October 2015 to March 2016 with the permission of Head of Department and Principal of Institute. Total 80 consecutive subjects were recruited for this study, 40 subjects were diagnosed cases of preeclampsia and 40 subjects having matched age, BMI and dietary habits were selected as control. 
The inclusion criteria were prim gravida with gestational age between 31 to 40 weeks and willing to participate for this study. The exclusion criteria for this study were women suffering from hypertension, cardiovascular diseases, adrenal gland diseases, liver diseases, abnormal embryo on ultrasound and those having some malignancy.

After giving detail information about the study, written consent from all participants was taken. $5 \mathrm{ml}$ venous blood was collected from antecubital vein under aseptic measurement. Blood samples were centrifuged at 3000 revolution per minute for 10 minutes then serum collected in polyethylene covered cap bottles were stored at $-20{ }^{\circ} \mathrm{C}$ until serum zinc levels were analyzed. After room temperature the sample for serum Zinc levels were analyzed on Atomic Absorption Spectrophotometer.

The data entered and analyzed by SPSS 16 . The serum Zinc was compared between two groups using independent student-t test.

\section{RESULTS}

The study consist of 80 subjects under observation from which 40 subjects were pregnant ladies without preeclampsia and 40 were as case group in which pregnant ladies with preeclampsia. The mean serum Zinc level in control was $0.88 \mathrm{SD} \pm 0.02$ while it was $0.71 \mathrm{SD} \pm 0.04$, the difference was statistically significant with a $p$ value of $<0.0001$ as shown in Table I.

TABLE I: SERUM ZINC LEVELS OF CONTROL \& CASES GROUPS

\begin{tabular}{|c|c|c|}
\hline Subjects & $\begin{array}{c}\text { Control } \\
\text { (40 subjects) }\end{array}$ & $\begin{array}{c}\text { Case } \\
(\mathbf{4 0} \text { subjects })\end{array}$ \\
\hline Serum Zinc $(\mathrm{mg} / \mathrm{L})$ & $0.88 \pm 0.02$ & $0.71 \pm 0.04^{*}$ \\
\hline
\end{tabular}

$\left({ }^{*}=p\right.$ value $\left.<0.0001\right)$

GRAPH I: SERUM ZINC LEVELS OF CONTROL \& CASES GROUPS

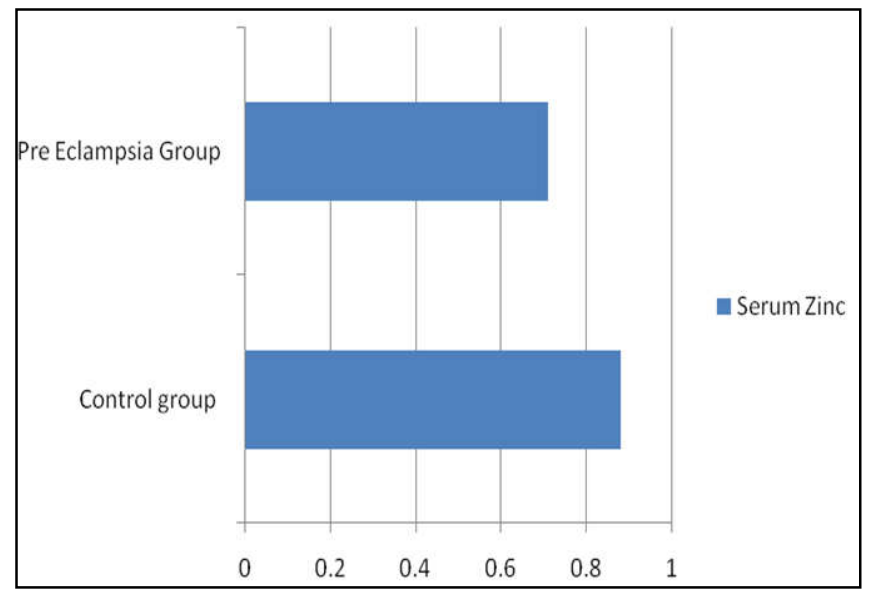

\section{DISCUSSION}

Preeclampsia, a multi factorial disease results on account of generation of oxidative stress in pregnant women. Enhanced production of free radicals and reduced levels of some trace elements necessary for antioxidant defense mechanisms are the important contributors to oxidative stress ${ }^{1}$

In the present study, "serum zinc concentration was found to decrease significantly in the preeclamptic group compared to normotensive pregnant women. Our results are consistent with earlier reports" 6,10,14.

$\mathrm{Zn}$ is an important trace element in metabolism, growth, development, and reproduction. This element plays important role in nucleic acid metabolism and protein synthesis, as well as membrane structure and function. ${ }^{15} \mathrm{Zn}$ deficiency has been associated with complications of pregnancy including preeclampsia. ${ }^{12}$

$\mathrm{Zn}$ is passively transferred from mother to fetus across the placenta, and there is also decreased $\mathrm{Zn}$ binding capacity of maternal blood during pregnancy, which facilitates efficient transfer of $\mathrm{Zn}$ from mother to fetus. During pregnancy, there is a decline in circulating $\mathrm{Zn}$ and this increases as the pregnancy progresses possibly due to decrease in $\mathrm{Zn}$ binding and increased transfer of $Z n$ from the mother to the fetus. ${ }^{8,16}$

$Z n$ is essential for proper growth of fetus and the fall in $\mathrm{Zn}$ during pregnancy could also be a physiological response to expanded maternal blood volume ${ }^{21}$. It was reported that an increased incidence of preeclampsia in $\mathrm{Zn}$-deficient regions may be corrected by $\mathrm{Zn}$ supplementation in those regions ${ }^{12}$.

Decreased levels of zinc observed in the preeclamptic group could be due to dilution of blood, transfer of this mineral from mother to the growing fetus and increased excretion of zinc in urine. Also the increased lipid peroxidation causes diminution in concentrations of transporter proteins and estrogen hormone that result in lower concentrations of zinc in pregnant women with preeclampsia ${ }^{17}$

The results of this study support the hypothesis that zinc is one of the good indicators of underlying hypertension in patients with abnormality in risk factors such as raised blood pressure and proteinuria that gradually leads to preeclampsia. It was also observed that decreased levels of these trace elements along with increased proteinuria may act as markers in prediction of preeclampsia in early stages of pregnancy ${ }^{11,17}$

Low serum level of zinc in the preeclamptic group observed in this study may also result in generation of oxidative stress. Zinc, is an important part of antioxidant enzymes required by the antioxidant defense system to protect cells from free radicals injury. It is an integral part of the antioxidant enzyme-superoxide dismutase (SOD). Decreased concentration of zinc in serum, may lead to decrease in activity of this 


\section{enzyme $^{18}$.}

Deficiency of these elements may withdraw the effect of antioxidant potential of cells leading to an increase in blood pressure ${ }^{19}$. Decreased levels of zinc observed in the preeclamptic group could be due to dilution of blood, transfer of this mineral from mother to the growing fetus and increased excretion of this mineral in urine. Also the increased lipid peroxidation causes diminution in concentrations of transporter proteins and estrogen hormone that result in lower concentrations of zinc in pregnant women with preeclampsia $^{20}$.

Through this study, the hypothesis that "zinc is good indicator of underlying hypertension in patients with abnormality in risk factors such as raised blood pressure and proteinuria that gradually leads to preeclampsia. We also pointed out that decreased levels of these trace elements along with increased proteinuria may act as markers in prediction of preeclampsia in early stages of pregnancy".

However, besides the disturbance in level of zinc element concentrations, disturbance in endothelial function and in sympathetic tone could be the additional factors that contribute to the pathogenesis of hypertension in pregnancy. ${ }^{21}$

\section{LIMITATION OF THE STUDY}

The present study has some limitations: we did not use proforma for rule out the dietary intake of preeclamptic women to find out whether the reduced levels of trace elements were due to nutritional deficiencies. Further study investigating the roles of dietary supplementation of these elements needs to be undertaken.

\section{REFERENCES}

1. Genc $H$, Uzun $H$, Benian $A$, et al. Evaluation of oxidative stress markers in first trimester for assessment of pre-eclampsia risk. Arch Gynecol Obstet. 2011;284(6):1367-73.

2. Jia RZ, Liu XM, Wang X, Wu HQ. Relationship between cardiovascular function and fetal growth restriction in women with pre-eclampsia. Int $\mathrm{J}$ Gynaecol Obstet. 2010;110:61-63.

3. Melchiorre K, Sutherland GR, Liberati M, Thilaganathan B. Preeclampsia is associated with persistent postpartum cardiovascular impairment. Hypertension. 2011;58(4):709-15.

4. Zamora-Kapoor A, Nelson LA, Buchwald DS, et al. Pre-eclampsia in American Indians / Alaska Natives and Whites: The Significance of Body Mass Index. Maternal Child Health J. 2016;20 (11):2233-38.

5. Shah N, Hossain N, Shoaib R, Hussain A, Gillani $\mathrm{R}$, Khan NH. Socio-demographic characteristics and the three delays of maternal mortality. J Coll
Physicians Surg Pak 2009; 19(2):95-8.

6. Khowaja AR, Mitton C, Bryan S, Magee LA, Bhutta ZA, von Dadelszen P. Economic evaluation of Community Level Interventions for Preeclampsia (CLIP) in South Asian and African countries: a study protocol. Implementation Science: IS 2015;10:76.

7. Fukada T, Yamasaki S, Nishida K, Murakami M, Hirano T. Zinc homeostasis and signaling in health and diseases: Zinc signaling. J Biol Inorg Chem. 2011;16(7):1123-34.

8. Biswas S, Roy A, Biswas S. Comparative study of copper, zinc, iron, ferritin, calcium and magnesium levels in pregnancy induced hypertension and normotensive primigravida mothers. IJRMS. 2016;4 (6):1879-83.

9. Bahadoran $P$, Zendehdel $M$, Movahedian $A$, Zahraee $\mathrm{RH}$.The relationship between serum zinc level and pre-eclampsia. Iran J Nurs Midwifery Res: 2010: 15(3):120-4.

10. Sen S, Rifas-Shiman SL, Shivappa N. et al. Dietary Inflammatory Potential during Pregnancy Is Associated with Lower Fetal Growth and Breastfeeding Failure: Results from Project Viva. J. Nutr. 2016:146 (4):728-36.

11. Anuradha R, Begum S. A Study of Serum Electrolytes in Normal Pregnancy and Pre-eclampsia and their Significance as a Diagnostic tool. IJAR. 2016;6(6):60-2.

12. Adam B, Malatyalioglu E, Alvur M, Talu C. Magnesium, zinc and iron levels in preeclampsia. J Matern Fetal Med; 2001:10(4); 246-50.

13. Lou Gol Muhammad S, Amirabi A, Yazdian M, Pashapour N. Evaluation of serum calcium, magnesium, copper, and zinc levels in women with preeclampsia. IJMS.2008: 33 (4): 231-34.

14. Zhu Q, Zhang L, Chen X, Zhou J, Liu J, Chen J. Association between zinc level and the risk of preeclampsia: a meta-analysis. Archives of gynecology and obstetrics. 2016; 293 (2):377-82.

15. Norrozi N, Borna S, Hanachi P, Faghihzadeh S, Haghollahi F, Golkhou Sh. Evaluation of zinc supplementation effect on fetal outcomes in pregnant women with lower than median serum zinc. J Family \& Reproductive Health. 2012; 6:85-91.

16. Tamura T, Goldenberg RL, Johnston KE, DuBard M. Maternal plasma zinc concentrations and pregnancy outcome. Am J Clin Nutr. 2000; 71(1): 109-13.

17. Chitra U, Mishra S, Ajmera P, Sharma P. Serum iron, copper and zinc status in maternal and cord blood. Indian J Clin Biochem. 2004;19(2):48-52.

18. Houghton LA, Parnell WR, Thomson CD, Green TJ, Gibson RS. Serum zinc is a major predictor of anemia and mediates the effect of selenium on 
hemoglobin in school-aged children in a nationally representative Survey in New Zealand. J.Nutr.2016;146(9):1670- 76.

19. Kunutsor SK, Laukkanen JA. Serum zinc concentrations and incident hypertension: new findings from a population-based cohort study. J Hypertens. 2016; 34(6):1055-61.

20. Kumru S, Aydin S, Simsek M, Sahin K, Yaman M,
Ay G. Comparison of serum copper, zinc, calcium, and magnesium levels in preclamptic and healthy pregnant women. Biol Trace Elem Res., 2003; 94 (2):105-12.

21. Siti HN, Kamisah $Y$, Kamsiah J. The role of oxidative stress, antioxidants and vascular inflammation in cardiovascular disease (a review). Vascul Pharmacol. 2015; 71:40-56.

AUTHOR AFFILIATION:

Dr. Ali Raza Memon

Lecturer, Department of Biochemistry

Liaquat University of Medical \& Health Sciences

(LUMHS), Jamshoro, Sindh-Pakistan.

Email: ali.bio.lumhs@gmail.com

Dr. Fareen Waryal Memon

Assistant Professor, Department of Gynecology \& Obstetrical

Indus Medical Collage Tando Muhammad Khan, Sindh-Pakistan.

Dr. Muhammad Akram

Associate Professor, Department of Biochemistry

Shaikh Khalifa Bin Zayed Al-Nahyan Medical \& Dental College

Lahore, Punjab-Pakistan.

Dr. Paras Javed Memon

MBBS Student

LUMHS, Jamshoro, Sindh-Pakistan.

Dr. Irtiza Rahman

MBBS Student

LUMHS, Jamshoro, Sindh-Pakistan. 